\title{
A Thermal Damage Constitutive Model for Oil Shale Based on Weibull Statistical Theory
}

\author{
Guijie Zhao ${ }^{(D)},{ }^{1}$ Chen Chen ${ }^{(D)},{ }^{2}$ and Huan Yan ${ }^{1}{ }^{1}$ \\ ${ }^{1}$ College of Civil Engineering, Changchun Institute of Technology, Changchun, China \\ ${ }^{2}$ College of Construction Engineering, Jilin University, Changchun, China
}

Correspondence should be addressed to Chen Chen; chenchen@jlu.edu.cn

Received 2 July 2019; Accepted 23 September 2019; Published 13 October 2019

Academic Editor: Pietro Bia

Copyright ( 2019 Guijie Zhao et al. This is an open access article distributed under the Creative Commons Attribution License, which permits unrestricted use, distribution, and reproduction in any medium, provided the original work is properly cited.

In this work, we first studied the thermal damage to typical rocks, assuming that the strength of thermally damaged rock microelements obeys a Weibull distribution and considering the influence of temperature on rock mechanical parameters; under the condition that microelement failure conforms to the Drucker-Prager criterion, the statistical thermal damage constitutive model of rocks after high-temperature exposure was established. On this basis, conventional triaxial compression tests were carried out on oil shale specimens heated to different temperatures, and according to the results of these tests, the relationship between the temperature and parameters in the statistical thermal damage constitutive model was determined, and the thermal damage constitutive model for oil shale was established. The results show that the thermal damage in oil shale increases with the increase of temperature; the damage variable is largest at $700^{\circ} \mathrm{C}$, reaching 0.636 ; from room temperature to $700^{\circ} \mathrm{C}$, the elastic modulus and Poisson's ratio decrease by $62.66 \%$ and $64.57 \%$, respectively; the theoretical stress-strain curve obtained from the model is in good agreement with the measured curves; the maximum difference between the two curves before peak strength is only $5 \times 10^{-4}$; the model accurately reflects the deformation characteristics of oil shale at high temperature. The research results are of practical significance to the underground in situ thermal processing of oil shale.

\section{Introduction}

Oil shale resources are abundant and, when converted into shale oil, will amount to more than 400 billion tons, which is approximately three times the proven recoverable reserve of natural crude oil. With the rapid growth of the economy and population, the demand for energy has increased sharply, while conventional oil and gas resources are decreasing. Against the background of this energy crisis, oil shale resources have attracted more attention because of their abundance and future development prospects [1-4].

To use the oil shale resources, many methods of exploitation of oil shale have been developed, which can be roughly divided into two categories: surface retorting and in situ thermal processing. In situ thermal processing techniques developed later than surface retorting but have developed rapidly. At present, there are more than ten in situ thermal processing techniques, the core of which relies on heating of the underground oil shale reservoir to produce oil and gas by pyrolysis of kerogen in oil shale and then recovering oil and gas to the surface $[5,6]$. In the process of in situ heating of an oil shale reservoir, thermal damage is bound to occur in the oil shale, and the damage will be aggravated continuously. Thermally damaged oil shale will undergo changes in microstructure and macrophysical and mechanical properties. In view of this, it is important to study the thermal damage to oil shale and establish an appropriate constitutive model thereof [7-9].

The thermal damage problems of typical rock were first studied. Assuming that the strength of thermally damaged rock microelements obeys a Weibull distribution, considering the influence of temperature on rock mechanical parameters, and defining the thermal damage variable under the condition that microelement failure conforms to the Drucker-Prager criterion, the statistical thermal damage constitutive model of rock after high-temperature exposure 
was established. Based on the concept of rock yield, the model parameters were determined by the extremum method. On this basis, according to the results of conventional triaxial compression tests of oil shale specimens after heating to different temperatures, the relationship between temperature $T$ and parameters in the statistical thermal damage constitutive model of oil shale after high-temperature exposure was determined by means of a mathematical fitting method, and the thermal damage constitutive model of oil shale was thus established. The correctness of the model was verified by comparing the theoretical stress-strain curve calculated from the model to the actual curve measured by conventional triaxial tests.

\section{Damage Model for Rock Based on Weibull Statistical Theory}

2.1. Statistical Strength Theory of Rock Failure. In 1939, Weibull took the lead in introducing statistical methods into the strength theory of materials to describe the nonuniformity of materials. He believed that the failure probability of materials can be calculated statistically when the stress is constant, although it may be inaccurate to measure the failure strength of materials. Kostak, based on uniaxial compression testing of 320 sandstone specimens, obtained the strength distribution cubic graph by statistical analysis and found that the strength of rock specimens has a certain discreteness, but on the whole, the strength of these discrete rocks has a certain statistical regularity. Tang Chun'an (1993) proposed a hypothesis whereby the strength of the rock microelement satisfies a certain statistical distribution. He proposed that mesoheterogeneity is the fundamental cause of the macro-nonlinearity of quasi-brittle materials and used the statistical damage method to consider the heterogeneity of rock materials and the randomness of defects.

Many experts have proposed statistical models to estimate the strength of materials during damage fracture or fatigue failure, among which the most important ones are those following the normal distribution, Weibull distribution, lognormal distribution, and gamma distribution [1015]. The Weibull distribution statistical model has strong adaptability and fitting ability and thus is the most widely used model. Its probability density function is as follows:

$$
f(x)= \begin{cases}\frac{m}{F}\left(\frac{x-\gamma}{F}\right)^{m-1} \exp \left[-\left(\frac{x-\gamma}{F}\right)^{m}\right], & x \in[\gamma, \infty), \\ 0, & x \in(-\infty, \gamma) .\end{cases}
$$

Its cumulative probability distribution function is

$$
F(x)=1-\exp \left[-\left(\frac{x-\gamma}{F}\right)^{m}\right], \quad x \in[\gamma, \infty),
$$

where $m$ is the shape parameter, $F$ is the scale parameter, and $\gamma$ represents the position parameter.

2.2. Damage Variable and Establishment of the Damage Constitutive Relationship. At present, there are two main ways in which to establish rock constitutive relationships by using damage theory: one is to establish a relationship [16] according to the principle of energy equivalence before and after damage; the other relies on the principle of strain equivalence before and after deformation. These two approaches establish the constitutive relationship of rock materials from different perspectives, but the mechanical concept of the latter is clearer. Therefore, in this research, the latter was used to establish the damage constitutive relationship of rock.

According to Lemaitre's equivalent strain hypothesis, the following results were obtained [17]:

$$
\left[\sigma^{*}\right]=\frac{[\sigma]}{1-[D]}=\frac{[E][\varepsilon]}{1-[D]}
$$

where $[\sigma]$ is the stress tensor, $\left[\sigma^{*}\right]$ denotes the effective stress tensor, $[\varepsilon]$ is the strain tensor, $[E]$ is the elastic modulus matrix, and $[D]$ is the damage matrix.

Rock has a certain residual strength after failure. Considering the influence of rock residual strength, the damage correction coefficient $\delta$ was used to modify equation (3) [18]:

$$
\left[\sigma^{*}\right]=\frac{[\sigma]}{1-\delta[D]}=\frac{[E][\varepsilon]}{1-\delta[D]} .
$$

The key to establishing the damage constitutive relationship of rock is to determine the damage variable. In previous studies, the strength of rock microelements is usually expressed by rock axial principal strain, but this method cannot reflect the influence of the complex stress state on the strength of rock microelements; therefore, considering the failure model and criterion of rocks, others have proposed a new expression of damage variables reflecting the strength of rock microelements [19-22]. It is assumed that the general failure criterion for rocks is

$$
f\left(\sigma^{*}\right)-k_{0}=0,
$$

where $k_{0}$ is a constant related to the cohesion and internal friction angle of rock.

$f\left(\sigma^{*}\right)$ reflects the criticality of rock microelement failure and can be used as the strength of a rock microelement. Assuming that the probability of rock microelement failure is $F\left[f\left(\sigma^{*}\right)\right]$, which is related to the distribution density of $f\left(\sigma^{*}\right)$, the damage variable $D$ is defined as follows:

$$
D=\int_{0}^{f\left(\sigma^{*}\right)} F(x) \mathrm{d} x .
$$

Formula (6) shows that the key to establishing the damage model for the entire process of rock deformation and failure lies in the determination of rock microelement strength and its failure probability.

2.3. Determination of Rock Microelement Strength. At present, there are many forms of failure criteria that can be used in rock mechanics research. Among them, the Drucker-Prager criterion has a simple parametric form that is applicable to rock media and is thus widely used. Therefore, the strength of a rock microelement based on the 
Drucker-Prager criterion was determined as follows $[12,16]$ :

$$
\begin{gathered}
f([\sigma])=k=\alpha_{0} I_{1}+\sqrt{J_{2}}, \\
\alpha_{0}=\frac{\sin \varphi}{\sqrt{9+3 \sin ^{2} \varphi}},
\end{gathered}
$$

where $\varphi$ is the internal friction angle; $I_{1}$ represents the first invariant of the stress tensor; and $J_{2}$ is the second invariant of the deviatoric stress tensor. The expressions of $I_{1}$ and $J_{2}$ are as follows:

$$
\begin{aligned}
& I_{1}=\sigma_{1}^{*}+\sigma_{2}^{*}+\sigma_{3}^{*}, \\
& J_{2}=\frac{1}{6}\left[\left(\sigma_{1}^{*}-\sigma_{2}^{*}\right)^{2}+\left(\sigma_{2}^{*}-\sigma_{3}^{*}\right)^{2}+\left(\sigma_{3}^{*}-\sigma_{1}^{*}\right)^{2}\right] .
\end{aligned}
$$

In conventional triaxial compression tests on rock specimens, nominal stresses $\sigma_{1}, \sigma_{2}$, and $\sigma_{3}\left(\sigma_{2}=\sigma_{3}\right)$ and strain $\varepsilon_{1}$ can be measured, and the corresponding effective stresses are $\sigma_{1}^{*}, \sigma_{2}^{*}$, and $\sigma_{3}^{*}\left(\sigma_{2}^{*}=\sigma_{3}^{*}\right)$. The formulae for calculating the effective stress are as follows:

$$
\begin{aligned}
& \sigma_{1}^{*}=\frac{\sigma_{1}}{1-\delta D}, \\
& \sigma_{2}^{*}=\sigma_{3}^{*}=\frac{\sigma_{3}}{1-\delta D} .
\end{aligned}
$$

The elastic modulus and Poisson's ratio of rock are $E$ and $\mu$, respectively. According to Hooke's law, the following result was obtained:

$$
\varepsilon_{1}=\frac{\left(\sigma_{1}^{*}-2 \mu \sigma_{3}^{*}\right)}{E} .
$$

Formulae (11)-(13) were substituted into formulae (9) and (10), and the following results were obtained:

$$
\left\{\begin{array}{l}
I_{1}=\frac{\left(\sigma_{1}+2 \sigma_{3}\right) E \varepsilon_{1}}{\sigma_{1}-2 \mu \sigma_{3}}, \\
\sqrt{J_{2}}=\frac{\left(\sigma_{1}-\sigma_{3}\right) E \varepsilon_{1}}{\sqrt{3}\left(\sigma_{1}-2 \mu \sigma_{3}\right)} .
\end{array}\right.
$$

By substituting formula (14) into formula (7), the strength of rock microelements was acquired as follows:

$$
f([\sigma])=\frac{E \varepsilon_{1}}{\sigma_{1}-2 \mu \sigma_{3}}\left[\left(\alpha_{0}+\frac{\sqrt{3}}{3}\right) \sigma_{1}+\left(2 \alpha_{0}-\frac{\sqrt{3}}{3}\right) \sigma_{3}\right] .
$$

2.4. Damage Model of Rock Based on Weibull Statistical Theory. Assuming that the strength $k$ of rock microelements obeys a Weibull distribution, the probability density function of rocks can be obtained from the Weibull statistical model introduced earlier as follows [16]:

$$
f(k)=\frac{m}{F}\left(\frac{k}{F}\right)^{m-1} \exp \left[-\left(\frac{k}{F}\right)^{m}\right] .
$$

where $k$ is the distribution variable of the Weibull distribution and $m$ and $F$ are Weibull distribution parameters. By substituting formula (16) into formula (6), the damage variable $D$ was calculated as follows:

$$
D=1-\exp \left[-\left(\frac{k}{F}\right)^{m}\right] .
$$

There is a threshold point $\left(\sigma_{\mathrm{D}}, \varepsilon_{\mathrm{D}}\right)$ in the damage evolution of rock materials. When the stress is less than the threshold point stress $\sigma_{\mathrm{D}}$, the damage of rocks is very small or no damage occurs. At this time, the damage variable can be considered to be zero and

$$
D=0, \quad \sigma_{1}<\sigma_{\mathrm{D}} .
$$

When the stress reaches or exceeds the threshold point stress $\sigma_{\mathrm{D}}$, the damage variable can be calculated according to equation (17). The damage variable expression of rock-like materials under arbitrary stress state can be expressed as follows:

$$
D= \begin{cases}0, & \sigma_{1}<\sigma_{\mathrm{D}}, \\ 1-\exp \left[-\left(\frac{k}{F}\right)^{m}\right], & \sigma_{1} \geq \sigma_{\mathrm{D}} .\end{cases}
$$

By substituting formulae (11), (12), and (17) into formula (13), the damage constitutive equation of rocks based on the Weibull distribution (after the damage threshold point, i.e., $\sigma_{1} \geq \sigma_{\mathrm{D}}$ ) was obtained as follows:

$$
\sigma_{1}=E \varepsilon_{1}\left\{1-\delta+\delta \exp \left[-\left(\frac{k}{F}\right)^{m}\right]\right\}-2 \mu \sigma_{3}, \quad \sigma_{1} \geq \sigma_{\mathrm{D}},
$$

where the parameter $m$ reflects the shape of the function; the parameter $F$ reflects the scale characteristics of the function and corresponds to the homogeneity and average strength of rock materials; and parameter $\delta$ reflects the residual strength of rocks.

Before reaching the damage threshold, i.e., $\sigma_{1}<\sigma_{\mathrm{D}}$, the constitutive relation of rock materials can be obtained by fitting the polynomial function relation. Considering that the strain of rocks is zero when the stress is zero, the relationship can be expressed as follows:

$$
\sigma_{1}=A \varepsilon_{1}\left(\varepsilon_{1}+B\right), \quad \sigma_{1}<\sigma_{\mathrm{D}},
$$

where $A$ and $B$ are coefficients.

By combining formulae (20) and (21), a rock damage model based on Weibull statistical theory under an arbitrary stress state was obtained as follows:

$$
\sigma_{1}= \begin{cases}A \varepsilon_{1}\left(\varepsilon_{1}+B\right), & \sigma_{1}<\sigma_{\mathrm{D}}, \\ E \varepsilon_{1}\left\{1-\delta+\delta \exp \left[-\left(\frac{k}{F}\right)^{m}\right]\right\}-2 \mu \sigma_{3}, & \sigma_{1} \geq \sigma_{\mathrm{D}} .\end{cases}
$$

\section{Thermal Damage Model of Rock}

3.1. Thermal Damage Evolution and Constitutive Equations. The room temperature is set to $25^{\circ} \mathrm{C}$. When the initial damage to rock materials is neglected, no thermal damage 
occurs at room temperature. If the elastic modulus is used to define the thermal damage variable $D_{\mathrm{T}}$, the following result can be obtained [23-30]:

$$
D_{\mathrm{T}}=1-\frac{E_{\mathrm{T}}}{E_{0}}
$$

where $E_{\mathrm{T}}$ and $E_{0}$ are the elastic modulus at temperature $T$ and $25^{\circ} \mathrm{C}$, respectively.

Weibull parameters of rocks at different temperatures are

$$
\begin{aligned}
& A_{\mathrm{T}}=A_{0}\left(1-D_{\mathrm{T}}\right), \\
& B_{\mathrm{T}}=B_{0}\left(1-D_{\mathrm{T}}\right), \\
& m_{\mathrm{T}}=m_{0}\left(1-D_{\mathrm{T}}\right), \\
& F_{\mathrm{T}}=F_{0}\left(1-D_{\mathrm{T}}\right),
\end{aligned}
$$

where $A_{0}, B_{0}, m_{0}$, and $F_{0}$ are the Weibull function parameters of rock materials at room temperature.

By substituting equation (7) into the damage evolution equation (19) of rock, the following results were obtained:

$$
D(\sigma, T)= \begin{cases}0, & \sigma_{1}<\sigma_{D}, \\ 1-\exp \left[-\left(\frac{\alpha_{0} I_{1}+\sqrt{J_{2}}}{F_{\mathrm{T}}}\right)^{m_{\mathrm{T}}}\right], & \sigma_{1} \geq \sigma_{\mathrm{D}} .\end{cases}
$$

The macroscopic elastic modulus changes obviously after the rock has been affected by a higher temperature. At this time, the change in elastic modulus can be considered to express the thermal damage effect of rocks. By substituting formula (23) into formula (28), the damage evolution equation of rock materials at different temperatures could be obtained as follows:

$$
D(\sigma, T)= \begin{cases}0, & \sigma_{1}<\sigma_{\mathrm{D}}, \\ 1-\exp \left[-\left(\frac{\alpha_{0} I_{1}+\sqrt{J_{2}}}{F_{0}\left(E_{\mathrm{T}} / E_{0}\right)}\right)^{m_{0}\left(E_{\mathrm{T}} / E_{0}\right)}\right], & \sigma_{1} \geq \sigma_{\mathrm{D}} .\end{cases}
$$

From equation (23), the elastic modulus of rocks at different temperatures was obtained as follows:

$$
E=E(T)=E_{\mathrm{T}}=E_{0}\left(1-D_{\mathrm{T}}\right) .
$$

By substituting equation (30) into equation (20), the thermal damage constitutive equation of rock materials based on conventional triaxial compression tests (after the damage threshold) could be obtained as follows:

$$
\sigma_{1}=E_{0}\left(1-D_{\mathrm{T}}\right) \varepsilon_{1}\left\{1-\delta+\delta \exp \left[-\left(\frac{\alpha_{0} I_{1}+\sqrt{J_{2}}}{F_{\mathrm{T}}}\right)^{m_{\mathrm{T}}}\right]\right\}+2 \mu \sigma_{3}
$$

By combining the constitutive equations before and after the damage threshold, i.e., formula (21) and formula (31), the thermal damage constitutive equation of rock materials based on conventional triaxial compression tests could be obtained as follows:

$\sigma_{1}= \begin{cases}A_{\mathrm{T}} \varepsilon_{1}\left[\varepsilon_{1}+B_{\mathrm{T}}\right], & 0 \leq \varepsilon \leq \varepsilon_{\mathrm{D}}, \\ E_{\mathrm{T}} \varepsilon_{1}\left\{1-\delta+\delta \exp \left[-\left(\frac{\alpha_{0} I_{1}+\sqrt{J_{2}}}{F_{\mathrm{T}}}\right)^{m_{\mathrm{T}}}\right]\right\}+2 \mu \sigma_{3}, & \varepsilon>\varepsilon_{\mathrm{D}} .\end{cases}$

3.2. Calculation of Parameters $A_{T}, B_{T}, m_{T}$, and $F_{T}$. The values of parameters $A_{\mathrm{T}}, B_{\mathrm{T}}, m_{\mathrm{T}}$, and $F_{\mathrm{T}}$ can be calculated by means of the stress and strain $\left(\sigma_{\mathrm{D}}, \varepsilon_{\mathrm{D}}\right)$ at the damage threshold point and those $\left(\sigma_{\mathrm{c}}, \varepsilon_{\mathrm{c}}\right)$ at the peak point on the rock stress-strain curve as measured by conventional triaxial compression tests. At the peak, the stress and strain satisfy the constitutive equation, and the first derivative of the stress-strain curve is zero at that point. The following results were obtained:

$$
\left\{\begin{array}{l}
\left.\sigma\right|_{\varepsilon=\varepsilon_{\mathrm{c}}}=\sigma_{\mathrm{c}} \\
\left.\frac{\partial \sigma}{\partial \varepsilon}\right|_{\varepsilon=\varepsilon_{\mathrm{c}}}=0
\end{array}\right.
$$

Regarding $m_{\mathrm{T}}$ and $F_{\mathrm{T}}$ as unknown, the above equations were solved, and the formulae for calculating parameters $m_{\mathrm{T}}$ and $F_{\mathrm{T}}$ were obtained as follows:

$$
m_{\mathrm{T}}=\frac{-f_{\mathrm{c}}\left(\left(\sigma_{\mathrm{c}}-2 \mu \sigma_{3}\right) /\left(E \varepsilon_{\mathrm{c}}\right)\right)\left[-\left(\alpha_{0}+(\sqrt{3} / 3)\right) E \varepsilon-10 \alpha_{0}+((5 \sqrt{3}) / 3)\right]}{E \varepsilon_{\mathrm{c}} \cdot\left(\left[\alpha_{0}\left(\sigma_{\mathrm{c}}+2 \sigma_{3}\right)+(\sqrt{3} / 3)\left(\sigma_{\mathrm{c}}-\sigma_{3}\right)\right] /\left(\sigma_{\mathrm{c}}-2 \mu \sigma_{3}\right)\right) \cdot\left(\ln \left(\sigma_{\mathrm{c}}-2 \mu \sigma_{3}+(\delta-1) E \varepsilon_{\mathrm{c}}\right) /\left(E \varepsilon_{\mathrm{c}} \delta\right)\right)} \cdot \frac{1}{\left(\left(\sigma_{\mathrm{c}}-2 \mu \sigma_{3}\right) /\left(E \varepsilon_{\mathrm{c}}\right)\right)+\delta-1},
$$

$$
F_{\mathrm{T}}=\frac{f_{\mathrm{c}}}{\left(\ln \left(\left(\sigma_{\mathrm{c}}-2 \mu \sigma_{3}+(\delta-1) E \varepsilon_{\mathrm{c}}\right) /\left(E \varepsilon_{\mathrm{c}} \delta\right)\right)\right)^{\left(1 / m_{\mathrm{T}}\right)}}
$$

where

$f_{\mathrm{c}}=E \varepsilon_{\mathrm{c}}\left(\left(\alpha_{0}\left(\sigma_{\mathrm{c}}+2 \sigma_{3}\right)-(\sqrt{3} / 3)\left(\sigma_{\mathrm{c}}-\sigma_{3}\right)\right) /\left(\sigma_{\mathrm{c}}-2 \mu \sigma_{3}\right)\right)$

The stress-strain curves of rocks are continuous at the threshold points and

$$
A_{\mathrm{T}} \varepsilon_{1}^{2}+A_{T} B_{\mathrm{T}} \varepsilon_{1}=E \varepsilon_{1}\left\{1-\delta+\delta \exp \left[-\left(\frac{f}{F_{\mathrm{T}}}\right)^{m_{\mathrm{T}}}\right]\right\}+2 \mu \sigma_{3} .
$$


The first derivative of the rock stress-strain curves is continuous at the threshold point and

$$
\left.\frac{\partial \sigma_{1}}{\partial \varepsilon_{1}}\right|_{\varepsilon_{1}=\varepsilon_{\mathrm{D}}}=2 A \varepsilon_{1}+A B .
$$

By combining formulae (36) and (37), we obtain

$$
\begin{aligned}
& A_{\mathrm{T}}=\frac{d \varepsilon_{\mathrm{D}}-2 \mu \sigma_{3}}{\varepsilon_{\mathrm{D}}^{2}}, \\
& B_{\mathrm{T}}=\frac{c \varepsilon_{\mathrm{D}}+d \varepsilon_{\mathrm{D}}^{2}}{d \varepsilon_{\mathrm{D}}-2 \mu \sigma_{3}}-2 \varepsilon_{\mathrm{D}},
\end{aligned}
$$

where $c=E \varepsilon_{\mathrm{D}}\left\{1-\delta+\delta \exp \left[-\left(f_{\mathrm{D}} / F\right)^{m}\right]\right\}$,

$$
\begin{aligned}
d= & E \varepsilon_{\mathrm{D}} \delta \cdot \exp \left[-\left(\frac{f_{\mathrm{D}}}{F}\right)^{m}\right] \cdot\left(-\frac{m f_{\mathrm{D}}^{m-1}}{F^{m}}\right) \\
& \cdot\left\{\alpha_{0}\left[\frac{\left(2 E^{2} \varepsilon_{\mathrm{D}}+2 \sigma_{3}\right)}{E \varepsilon_{\mathrm{D}}-2 \mu \sigma_{3}}-\frac{\left(E \varepsilon_{\mathrm{D}}+2 \sigma_{3}\right) E^{2} \varepsilon_{\mathrm{D}}}{\left(E \varepsilon_{\mathrm{D}}-2 \mu \sigma_{3}\right)^{2}}\right]\right. \\
& \left.+\frac{2 E^{2} \varepsilon_{\mathrm{D}}-E \sigma_{3}}{\sqrt{3}\left(E \varepsilon_{\mathrm{D}}-2 \mu \sigma_{3}\right)}-\frac{\sqrt{3} E^{2} \varepsilon_{\mathrm{D}}\left(E \varepsilon_{\mathrm{D}}-\sigma_{3}\right)}{3\left(E \varepsilon_{\mathrm{D}}-2 \mu \sigma_{3}\right)^{2}}\right\}, \\
f_{\mathrm{D}}= & E \varepsilon_{\mathrm{D}} \frac{\alpha_{0}\left(\sigma_{\mathrm{D}}+2 \sigma_{3}\right)-(\sqrt{3} / 3)\left(\sigma_{\mathrm{D}}-\sigma_{3}\right)}{\sigma_{\mathrm{D}}-2 \mu \sigma_{3}} .
\end{aligned}
$$

3.3. Physical Meaning of Parameters. Through mathematical analysis of the equation, the physical meaning of parameters $m$, $F, A, B$, and $\delta$ is obtained: $m$ reflects the morphological characteristics of the stress-strain curve, and the smaller $m$ is, the shallower the stress-strain curve is and the tougher the rock is; $F$ represents the average strength of rocks, and when $F$ increases, the peak strength of rocks increases accordingly; $A$ represents the concavity in the compacting stage, and the larger $A$ is, the more notable the upwards concavity is; $B$ is the initial elastic modulus of rocks; and $\delta$ reflects the residual strength thereof (the larger $\delta$ is, the lower the residual strength is).

\section{Thermal Damage Tests on Oil Shale Specimens}

The oil shale used in this study was sampled from Yong'an Township, Nong'an County, Jilin Province, China (Figure 1). The rocks are gray-black, the horizontal bedding planes are well developed, the rocks contain a large number of crustal fossils, and the density of rocks ranges from 1.92 to $2.11 \mathrm{~g} / \mathrm{cm}^{3}$. To simulate the heating of oil shale during in situ thermal processing more accurately, thermogravimetric analysis was carried out to determine the temperature range required for heating, and then the oil shale specimens were heated by special equipment [31].

4.1. Thermogravimetric Analysis of Oil Shale. The thermogravimetric curve (Figure 2) of oil shale specimens can be measured by a thermogravimetric analyzer (Figure 3 ). The

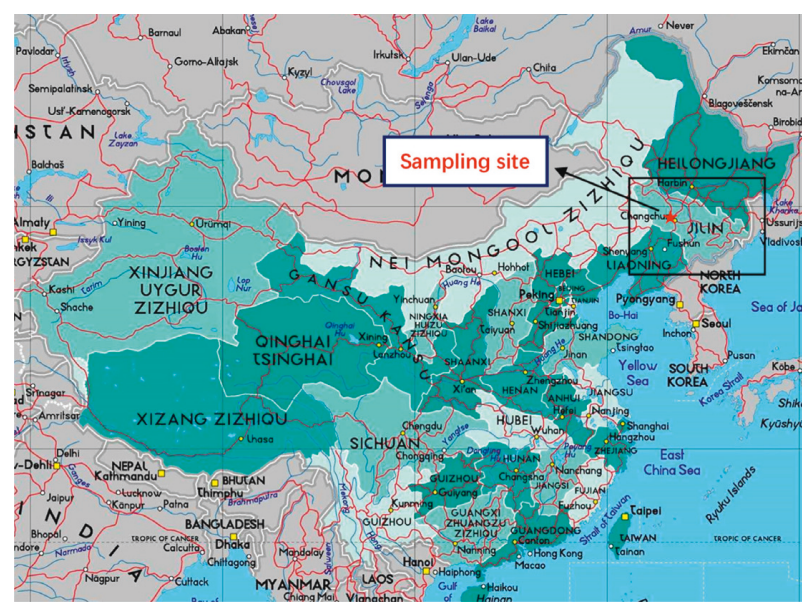

Figure 1: Location map of the sampling site in China.

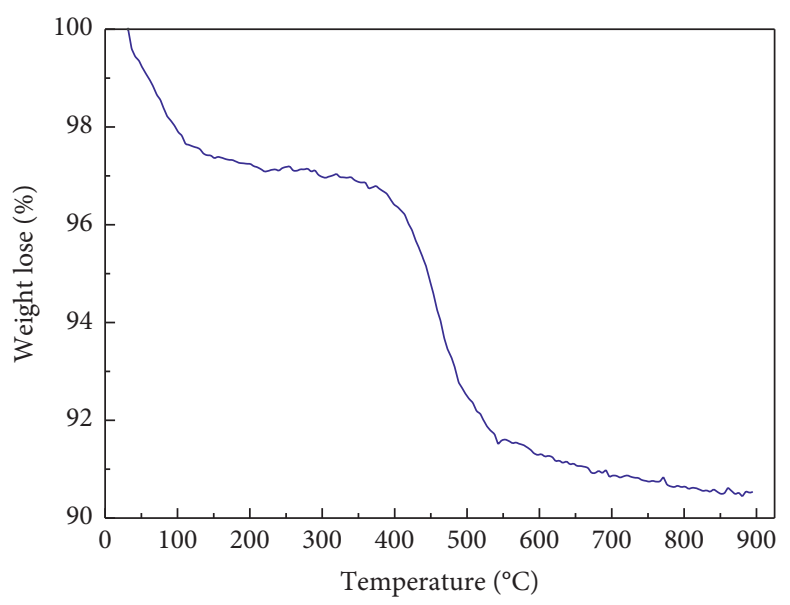

Figure 2: Thermogravimetric curve.

thermogravimetric curve was used to analyze the possible temperature range of oil shale during in situ thermal processing, and the temperature range of oil shale thermal damage tests in the present work was determined accordingly. Through analysis of Figure 2, the following conclusions can be drawn: the pyrolysis of kerogen, which produces shale oil (gas) and combustible gas, occurs between $400^{\circ} \mathrm{C}$ and $500^{\circ} \mathrm{C}$. If the kerogen is to be fully pyrolyzed, only the oil shale is heated to the upper temperature bounding the high-temperature weight-loss stage; therefore, in this experiment, the temperature range from room temperature to $700^{\circ} \mathrm{C}$ is chosen to study thermal damage to oil shale specimens. The possible temperatures of oil shale in all in situ thermal processing modes are basically in this range (room temperature to $700^{\circ} \mathrm{C}$ ) thus ensuring that the research results are representative.

4.2. Heating Tests on Oil Shale Specimens. According to prevailing requirements, the oil shale blocks were processed into a cylinder with a diameter of $50 \mathrm{~mm}$ and a height of $100 \mathrm{~mm}$ perpendicular to the bedding direction (Figure 4). They were heated by an MXG1200-80 tubular furnace. The experiment was carried out in eight groups. The heating 


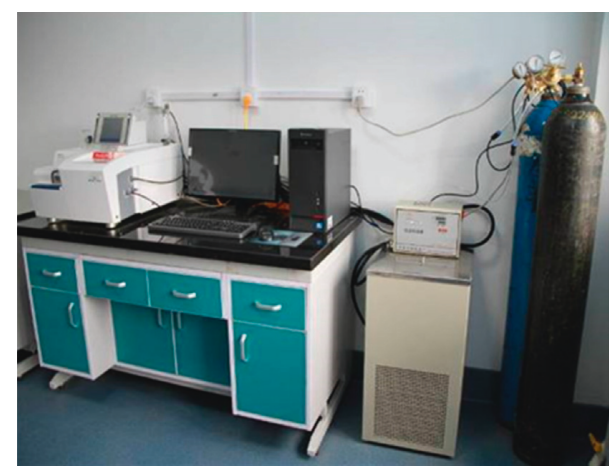

FIgURE 3: Thermogravimetric analyzer.

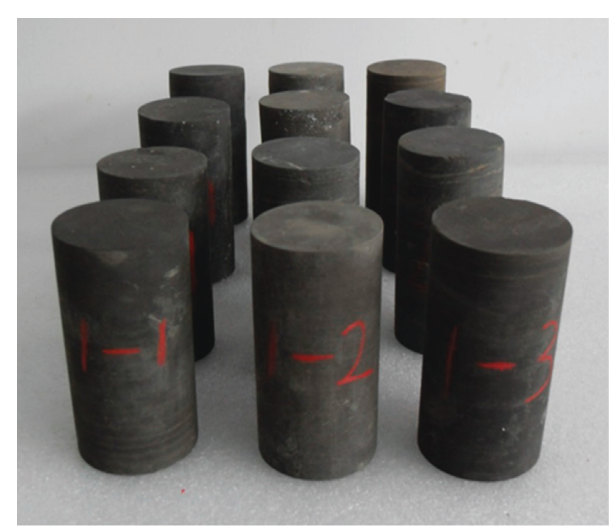

FIgURE 4: Typical oil shale specimens.

temperatures of the groups were set to $25^{\circ} \mathrm{C}$ (room temperature), $100^{\circ} \mathrm{C}, 200^{\circ} \mathrm{C}, 300^{\circ} \mathrm{C}, 400^{\circ} \mathrm{C}, 500^{\circ} \mathrm{C}, 600^{\circ} \mathrm{C}$, and $700^{\circ} \mathrm{C}$, respectively. To ensure uniformity of heating, heating was carried out at a rate of $5^{\circ} \mathrm{C} / \mathrm{min}$. After reaching the predetermined temperature, the temperature was maintained for $4 \mathrm{~h}$, and then, specimens were naturally cooled to room temperature in the furnace tube. The heated oil shale specimens are as shown in Figure 5, and they were used in the following conventional triaxial compression tests.

\subsection{Conventional Triaxial Compression Tests on Thermally} Damaged Oil Shale Specimens. For thermally damaged oil shale after heating, the conventional triaxial compression tests were carried out with a TAW-2000 triaxial rock-testing machine. Load control mode, a loading rate of $0.2 \mathrm{kN} / \mathrm{s}$, and a confining pressure of $5 \mathrm{MPa}$ were adopted; the axial deformations of the specimens were measured by a $10 \mathrm{~mm}$ extensometer, and the radial deformations were measured by a $5 \mathrm{~mm}$ extensometer. The axial force was measured by a pressure sensor with a range of $2000 \mathrm{kN}$, while confining pressure was measured by a pressure sensor with a range of $100 \mathrm{MPa}$. Three specimens were selected for parallel tests at the same temperature. Figure 6 shows the triaxial rocktesting machine selected for these tests, and Figure 7 shows an oil shale specimen after compressive failure.

Figure 8 shows the stress-strain curves of eight groups of oil shale specimens in conventional triaxial compression tests $\left(\sigma_{3}=5 \mathrm{MPa}\right)$.

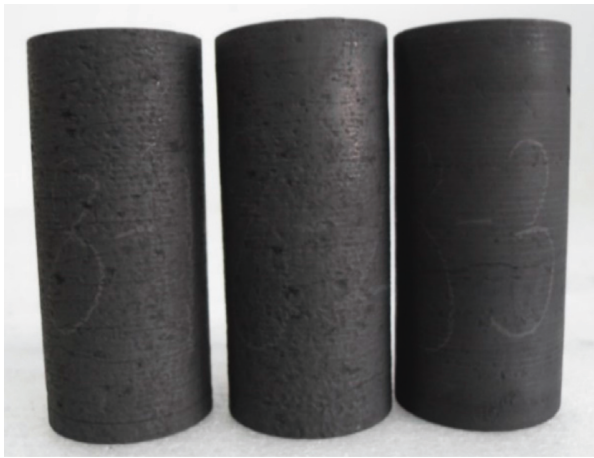

Figure 5: Heated $\left(700^{\circ} \mathrm{C}\right)$ specimens.

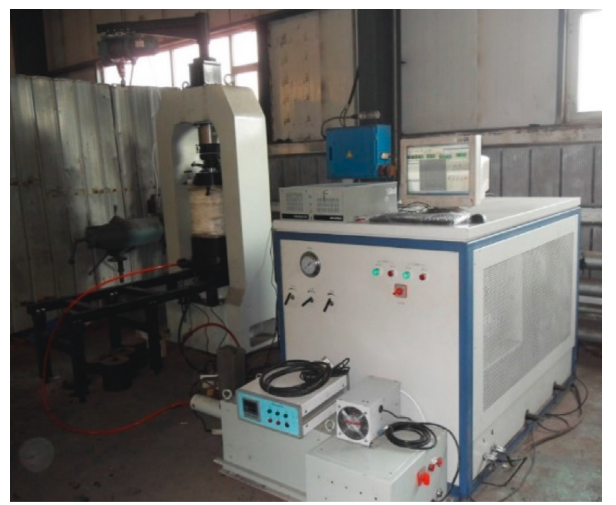

Figure 6: TAW-2000 triaxial rock-testing machine.

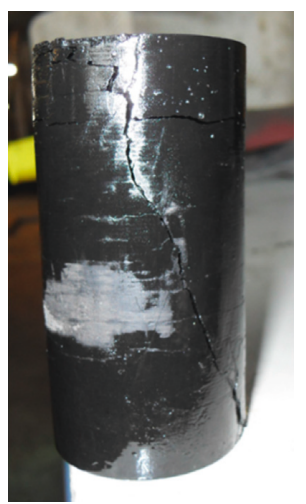

FIgURE 7: Compressive failure.

Through the analysis of Figure 8, it can be found that the peak strength and slope of the elastic stage decrease with the increase of heating temperature. In addition, the compacting stage of the stress-strain curve becomes longer than that before $400^{\circ} \mathrm{C}$ when the temperature exceeds $400^{\circ} \mathrm{C}$. The results indicate that the thermal damage in oil shale specimens increases with increasing temperature.

\section{Establishment and Verification of the Thermal Damage Constitutive Model for Oil Shale}

5.1. Determination of Elastic Moduli, Poisson's Ratios, and Thermal Damage Variables. According to the stress-strain 


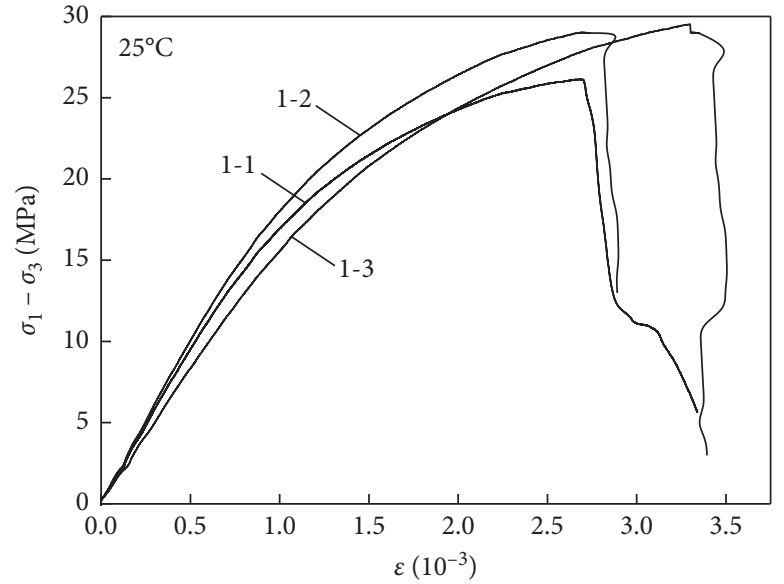

(a)

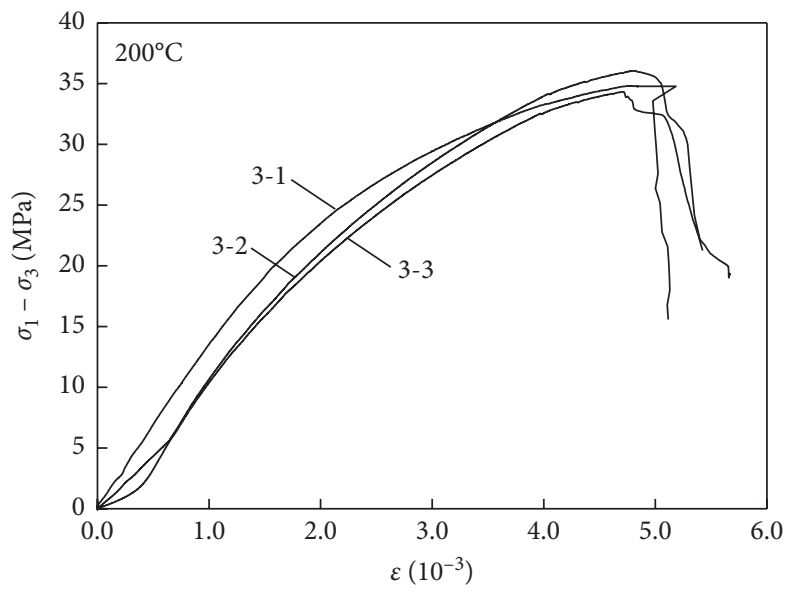

(c)

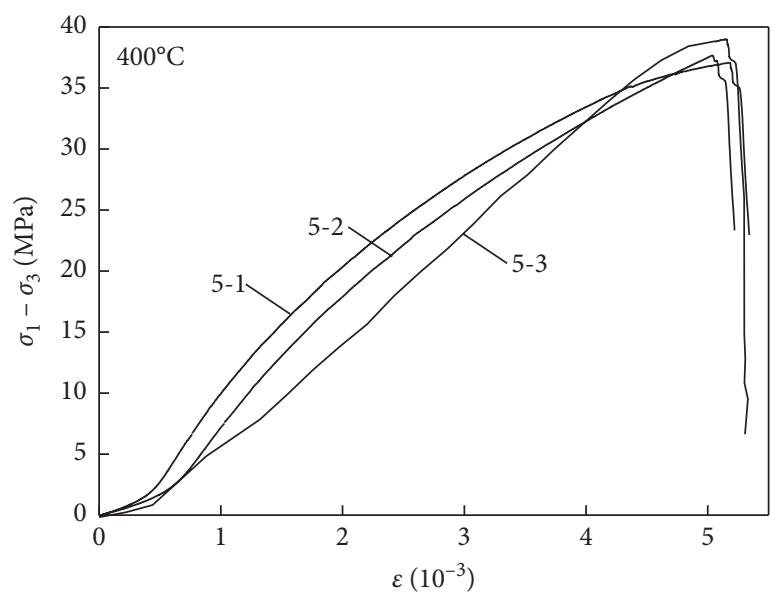

(e)

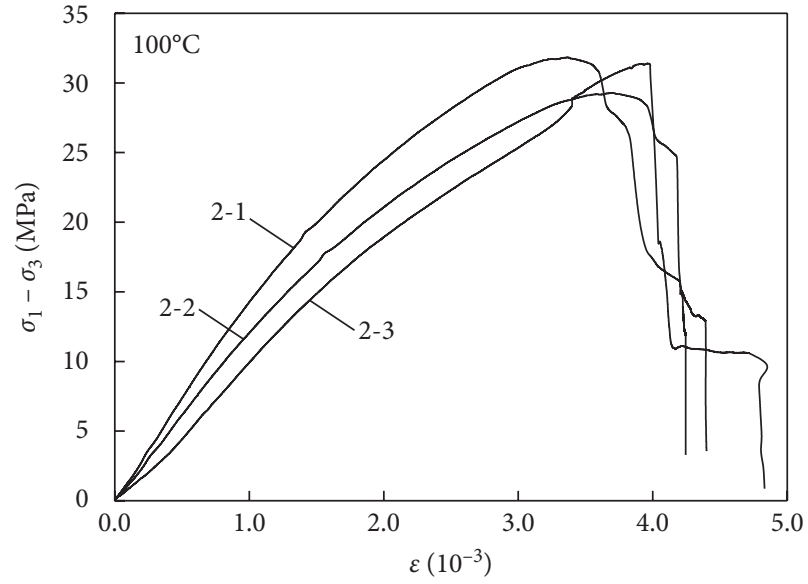

(b)

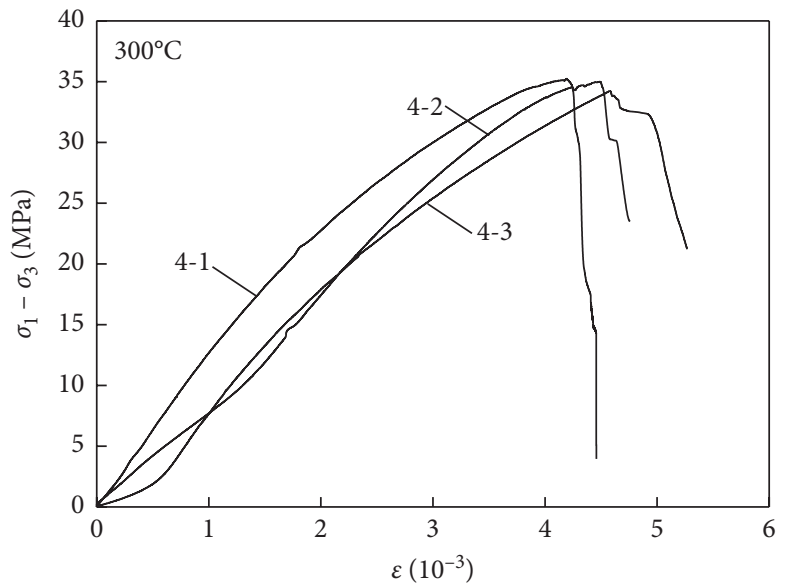

(d)

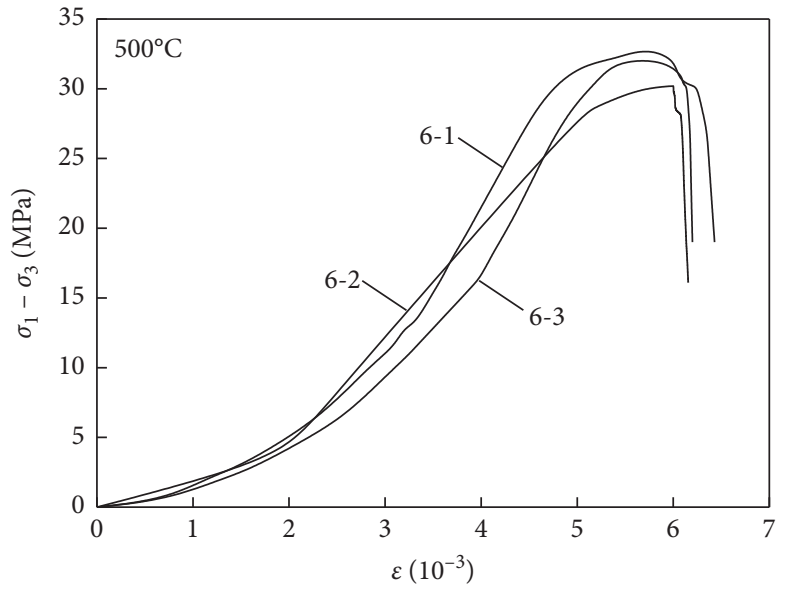

(f)

Figure 8: Continued. 


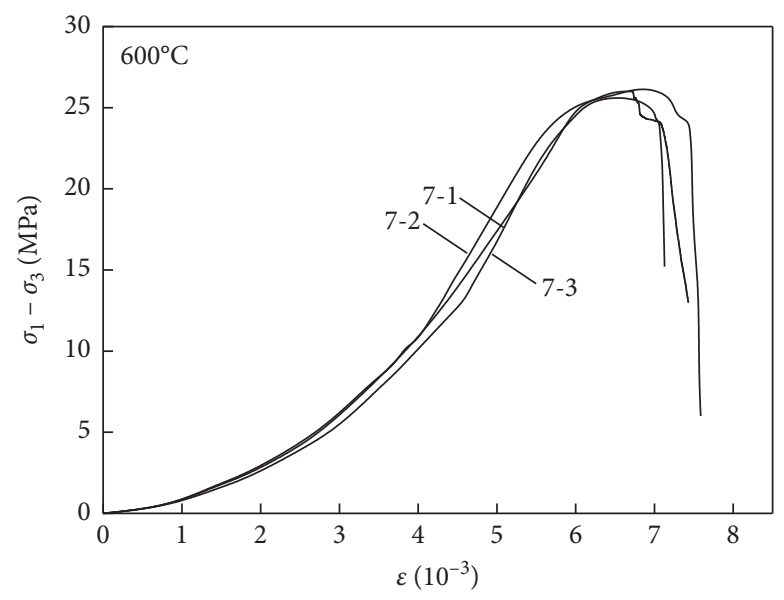

(g)

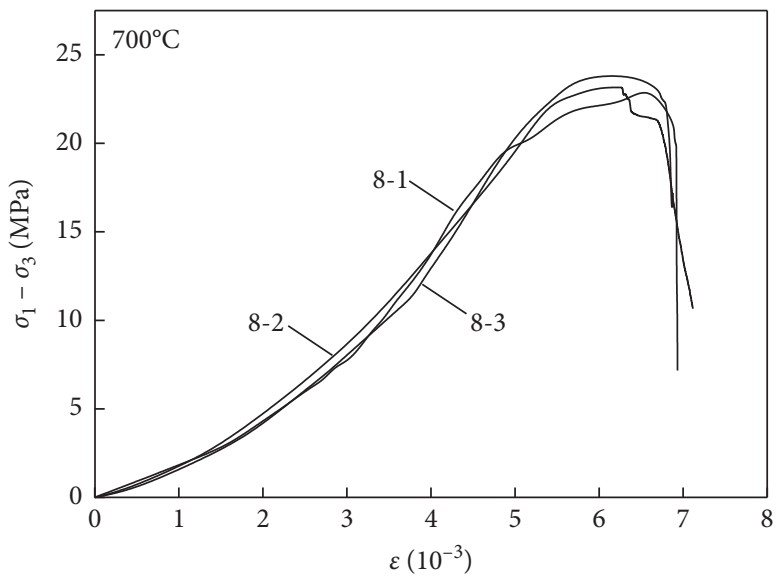

(h)

FIGURE 8: Stress-strain curves.

curves of oil shale specimens at different temperatures (Figure 7), the elastic moduli of each specimen were calculated by choosing the elastic stage before the peak strength, and then Poisson's ratios of oil shale specimens were calculated by the ratio of radial strain to axial strain (Table 1).

Based on the elastic moduli in Table 1, the thermal damage variable $D_{T}$ of oil shale specimens at different temperatures was calculated by using equation (19). The results are listed in Table 2.

5.2. Determination of Model Parameters $A_{T}, B_{T}, m_{T}$, and $F_{T}$. According to the conventional triaxial compression test results, the specific values of $m_{\mathrm{T}}$ and $F_{\mathrm{T}}$ at different temperatures were calculated by using formulae (34) and (35), respectively. Among them, the value of $\delta$ is 0.95 , the stress and strain at the peak point $\left(\sigma_{\mathrm{c}}, \varepsilon_{\mathrm{c}}\right)$ of the stress-strain curve are the average of stress and strain at the peak point of three specimens, the internal friction angle is $30^{\circ}$, and the calculated value of $\alpha_{0}$ is 0.16 . The calculated values of parameters $A_{\mathrm{T}}, B_{\mathrm{T}}, m_{\mathrm{T}}$, and $F_{\mathrm{T}}$ at different temperatures are as listed in Table 3 . The variations of constitutive equation parameters $A_{\mathrm{T}}, B_{\mathrm{T}}, m_{\mathrm{T}}$, and $F_{\mathrm{T}}$ with temperature are shown in Figure 9.

By fitting the data in Table 3 , the mathematical relationships between model parameters $A_{\mathrm{T}}, B_{\mathrm{T}}, m_{\mathrm{T}}$, and $F_{\mathrm{T}}$ and temperature $T$ were obtained:

$$
\begin{array}{cc}
A_{\mathrm{T}}=-21.9 \times 10^{7} \times \exp \left(-\frac{T}{343.735}\right)+2.8 \times 10^{6}, & R^{2}=0.989, \\
B_{\mathrm{T}}=-3.285 \times 10^{-4} \times \exp \left(\frac{T}{217.9}\right)-1.128 \times 10^{-3}, & R^{2}=0.977, \\
m_{\mathrm{T}}=-3.141 \times 10^{-8} T^{3}+1.207 \times 10^{-5} T^{2}+0.0103 T+2.962 & R^{2}=0.95 \\
F_{\mathrm{T}}=1.26 \times 10^{-7} T^{3}-2.4 \times 10^{-4} T^{2}+0.11 T+36.2, & R^{2}=0.85 .
\end{array}
$$

TABle 1: Elastic moduli and Poisson's ratios of oil shale specimens at different temperatures.

\begin{tabular}{lccccc}
\hline $\begin{array}{l}\text { Temperature } \\
\left({ }^{\circ} \mathrm{C}\right)\end{array}$ & \multicolumn{4}{c}{ Elastic modulus $(\mathrm{GPa})$} & Poisson's \\
\hline 25 & 1 & 2 & 3 & Average & ratio \\
100 & 18.649 & 17.375 & 18.932 & 18.319 & 0.460 \\
200 & 11.992 & 12.400 & 13.973 & 12.788 & 0.469 \\
300 & 12.319 & 12.856 & 13.044 & 12.740 & 0.434 \\
400 & 10.585 & 11.004 & 11.134 & 10.908 & 0.427 \\
500 & 9.795 & 9.161 & 9.601 & 9.519 & 0.276 \\
600 & 8.800 & 8.407 & 8.885 & 8.697 & 0.272 \\
700 & 8.333 & 7.644 & 8.658 & 8.212 & 0.195 \\
\hline
\end{tabular}

5.3. Thermal Damage Constitutive Model for Oil Shale. The values of, or mathematical expressions for, the parameters required in the model have been determined, and the thermal damage constitutive equation of oil shale can be obtained as follows:

$\sigma_{1}= \begin{cases}A_{\mathrm{T}} \varepsilon_{1}\left[\varepsilon_{1}+B_{\mathrm{T}}\right], & 0 \leq \varepsilon \leq \varepsilon_{\mathrm{D}}, \\ E_{\mathrm{T}} \varepsilon_{1}\left\{1-\delta+\delta \exp \left[-\left(\frac{\alpha_{0} I_{1}+\sqrt{J_{2}}}{F_{\mathrm{T}}}\right)^{m_{\mathrm{T}}}\right]\right\}+2 \mu \sigma_{3}, & \varepsilon>\varepsilon_{\mathrm{D}},\end{cases}$

where $A_{\mathrm{T}}=-2.28 \times 10^{7} \times \exp (-(T / 353.75))+3.36 \times 10^{6}$; $B_{\mathrm{T}}=-3.48 \times 10^{-4} \times \exp (T / 192.4)-8.19 \times 10^{-4} ; \quad m_{\mathrm{T}}=1.946$ $\times 10^{-5} T^{2}+0.00757 T+4.251 ; \quad F_{\mathrm{T}}=2.4 \times 10^{-7} T^{3}-3.95 \times 10^{-}$ $4 T^{2}+0.134 T+33.5 ; I_{1}$ is the first invariant of the stress tensor, $I_{1}=\left(\left(\sigma_{1}+2 \sigma_{3}\right) E \varepsilon_{1}\right) /\left(\sigma_{1}-2 \mu \sigma_{3}\right) ; J_{2}$ is the second invariant of the deviatoric stress tensor; $\sqrt{J_{2}}=\left(\left(\sigma_{1}-\sigma_{3}\right) E \varepsilon_{1}\right) /$ $\left(\sqrt{3}\left(\sigma_{1}-2 \mu \sigma_{3}\right)\right) ; \alpha_{0}=\sin \varphi /\left(\sqrt{9+3 \sin ^{2} \varphi}\right) ; \varphi$ is the internal friction angle; and $\delta$ reflects the residual strength (the larger $\delta$ is, the lower the residual strength is).

5.4. Verification of the Thermal Damage Constitutive Model for Oil Shale. The theoretical stress-strain curve for oil shale at $600^{\circ} \mathrm{C}$ was calculated by the constitutive equation established above, and the theoretical curve was compared 
TABLE 2: Thermal damage variables of oil shale specimens at different temperatures.

\begin{tabular}{lcccccccc}
\hline Temperature $\left({ }^{\circ} \mathrm{C}\right)$ & 25 & 100 & 200 & 300 & 400 & 500 & 600 & 700 \\
\hline$D_{\mathrm{T}}$ & 0 & 0.302 & 0.305 & 0.405 & 0.480 & 0.525 & 0.546 & 0.636 \\
\hline
\end{tabular}

TABle 3: Constitutive model parameters at different temperatures.

\begin{tabular}{lccccccc}
\hline Temperature $\left({ }^{\circ} \mathrm{C}\right)$ & 25 & 100 & 200 & 300 & 400 & 500 & 700 \\
\hline$A_{\mathrm{T}}\left(\times 10^{6}\right)$ & -17.86 & -13.38 & -8.65 & -7.07 & -4.47 & -6.11 & -0.23 \\
$B_{\mathrm{T}}\left(\times 10^{-3}\right)$ & -1.61 & -1.66 & -2.18 & -2.31 & -2.60 & -2.20 & -9.06 \\
$m_{\mathrm{T}}$ & 3.33 & 6.43 & 4.95 & 6.59 & 7.09 & 6.68 & 5.42 \\
$F_{\mathrm{T}}$ & 39.42 & 44.54 & 47.62 & 52.37 & 51.00 & 44.83 \\
\hline
\end{tabular}

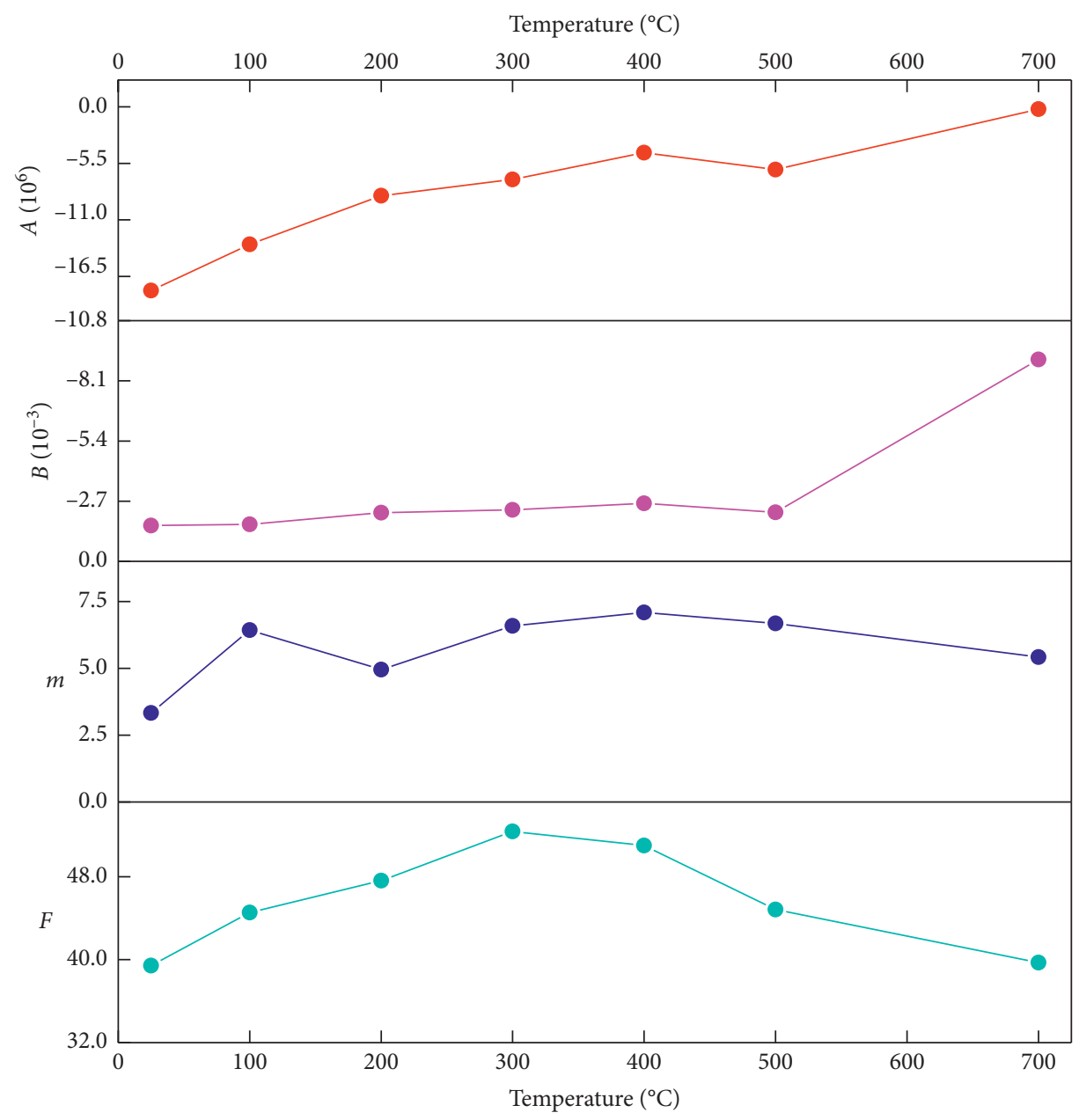

FIGURE 9: Variations of constitutive equation parameters with temperature.

with the measured curves to verify the correctness of the model.

It can be found from Figure 10 that the theoretical curve is in good agreement with the measured curves, especially before the peak point. The hypothesis and factors deemed negligible in the process of establishing the governing equation and parameter determination have little influence on the correctness of the equation. The constitutive model accurately reflects the deformation characteristics of oil shale at high temperatures. 


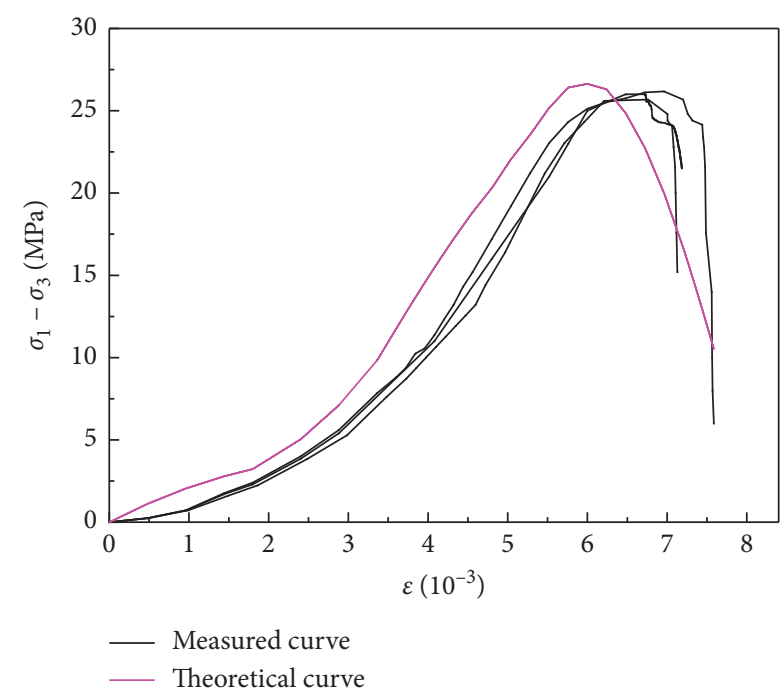

Figure 10: Comparison of theoretical and measured stress-strain curves at $600^{\circ} \mathrm{C}$.

\section{Conclusions}

(1) Assuming that the strength of thermally damaged rock microelements obeys a Weibull distribution, considering the influence of temperature on rock mechanical parameters, defining the thermal damage variable by elastic modulus, and under the condition that microelement failure conforms to the Drucker-Prager criterion, the statistical thermal damage constitutive model of rock after high-temperature exposure was established. The constitutive model is suitable for typical rocks including oil shale, and the effect of temperature on the stress-strain relationship is considered. The mathematical expressions of parameters $A_{\mathrm{T}}, B_{\mathrm{T}}, m_{\mathrm{T}}$, and $F_{\mathrm{T}}$ in the model do not include the unconventional rock mechanics parameters, and the specific values can be determined according to the conventional triaxial compression test results.

(2) The pyrolysis of kerogen in oil shale occurs mainly in the temperature range from room temperature to $700^{\circ} \mathrm{C}$, of which $400-500^{\circ} \mathrm{C}$ is the most concentrated. From room temperature to $700^{\circ} \mathrm{C}$, with the increase of temperature, the elastic modulus of oil shale decreases gradually from $18.319 \mathrm{GPa}$ to $6.841 \mathrm{GPa}$, which is a decrease of $62.66 \%$; Poisson's ratio of oil shale decreases gradually in the whole from 0.460 to 0.163 , which is a decrease of $64.57 \%$. With the increase of temperature, the thermal damage of oil shale is aggravated, and the damage variable increases continuously. At $700^{\circ} \mathrm{C}$, the damage variable is the largest, reaching 0.636 .

(3) According to the results of the triaxial compression test of oil shale, the values of model parameters in the statistical thermal damage constitutive model of rock at different temperatures were calculated, the relationship between model parameters and temperature $T$ was obtained by a mathematical fitting method, and the thermal damage constitutive model for oil shale was established. The parameters $A_{\mathrm{T}}, B_{\mathrm{T}}, m_{\mathrm{T}}$, and $F_{\mathrm{T}}$ of the model are no longer related to the rock mechanics parameters but only to the temperature $T$, which is convenient for engineering application.

(4) Comparing the theoretical stress-strain curve calculated by the model with those measured by conventional triaxial tests at $600^{\circ} \mathrm{C}$, the theoretical strain values are slightly smaller than the measured strain values, but the difference between them is not large; the maximum difference before the peak strength is only $5 \times 10^{-4}$, and the difference does not increase with the increase of strain. This result shows that the theoretical results are in good agreement with the conventional test results and that the model accurately reflects the deformation characteristics of oil shale at high temperature.

\section{Data Availability}

The data used to support the findings of this study are available from the corresponding author upon request.

\section{Conflicts of Interest}

The authors declare that they have no conflicts of interest.

\section{Acknowledgments}

This work was supported by the Youth Fund Project of Changchun Institute of Technology (grant no. 320180014).

\section{References}

[1] O. S. Al-Ayed, M. Matouq, Z. Anbar, A. M. Khaleel, and E. Abu-Nameh, "Oil shale pyrolysis kinetics and variable activation energy principle," Applied Energy, vol. 87, no. 4, pp. 1269-1272, 2010.

[2] S. Deng, Z. Wang, Q. Gu, F. Meng, J. Li, and H. Wang, "Extracting hydrocarbons from Huadian oil shale by subcritical water," Fuel Processing Technology, vol. 92, no. 5, pp. 1062-1067, 2011.

[3] J. R. Dyni, "Geology and resources of some world oil-shale deposits," Oil Shale, vol. 20, no. 3, pp. 193-252, 2003.

[4] J. Soone and S. Doilov, "Sustainable utilization of oil shale resources and comparison of contemporary technologies used for oil shale processing," Oil Shale, vol. 20, no. 4, pp. 311-323, 2003.

[5] M. Niu, S. Wang, X. Han, and X. Jiang, "Yield and characteristics of shale oil from the retorting of oil shale and fine oilshale ash mixtures," Applied Energy, vol. 111, pp. 234-239, 2013.

[6] Y. P. Wang, Y. W. Wang, X. L. Meng et al., "Enlightenment of American's oil shale in-situ retorting technology," Oil Drilling \& Production Technology, vol. 35, no. 6, pp. 55-59, 2013.

[7] M. K. Jha, A. K. Verma, S. Maheshwar, and A. Chauhan, "Study of temperature effect on thermal conductivity of Jhiri shale from Upper Vindhyan, India," Bulletin of Engineering Geology and the Environment, vol. 75, no. 4, pp. 1657-1668, 2016. 
[8] A. K. Verma, M. K. Jha, S. Maheshwar, T. N. Singh, and R. K. Bajpai, "Temperature-dependent thermophysical properties of Ganurgarh shales from Bhander group, India," Environmental Earth Sciences, vol. 75, no. 4, p. 300, 2016.

[9] M. K. Jha, A. K. Verma, P. K. Gautam, and A. Negi, "Study of mechanical properties of Vindhayan shaly rocks at elevated temperature," Journal of the Geological Society of India, vol. 90, no. 3, pp. 267-272, 2017.

[10] W. H. Xie, F. Gao, and H. P. Xie, “An experimental study on rock thermal damage fracture under meso-size," Journal of Experimental Mechanics, vol. 20, no. 4, pp. 628-634, 2005.

[11] W. G. Cao, Z. L. Fang, and X. J. Tang, "A study of statistical constitutive model for soft and damage rocks," Chinese Journal of Rock Mechanics Engineering, vol. 17, no. 6, pp. 628-633, 1998.

[12] W. G. Cao, M. H. Zhao, and X. J. Tang, "Study on simulation of statistical damage in the full process of rock failure," Chinese Journal of Geotechnical Engineering, vol. 25, no. 2, pp. 184-187, 2003.

[13] M. Zhang, F. Wang, and Q. Yang, "Statistical damage constitutive model for rocks based on triaxial compression tests," Chinese Journal of Geotechnical Engineering, vol. 35, no. 11, pp. 1965-1971, 2013.

[14] Y. Wang, Z. Liu, H. Yang, Z. Shao, and Z. Zhuang, "FE analysis of rock with hydraulic-mechanical coupling based on continuum damage evolution," Mathematical Problems in Engineering, vol. 2016, Article ID 8534965, 9 pages, 2016.

[15] X.-L. Xu, M. Karakus, F. Gao, and Z.-Z. Zhang, "Thermal damage constitutive model for rock considering damage threshold and residual strength," Journal of Central South University, vol. 25, no. 10, pp. 2523-2536, 2018.

[16] W. G. Cao, M. H. Zhao, and C. X. Liu, "Study on the model and its modifying method for rock softening and damage based on Weibull random distribution," Chinese Journal of Rock Mechanics and Engineering, vol. 23, no. 19, pp. 32263231, 2004.

[17] J. Lemaitre, "How to use damage mechanics," Nuclear Engineering and Design, vol. 80, no. 3, pp. 233-245, 1984.

[18] S. C. Li, J. Xu, K. G. Li, Y. Q. Tao, and X. J. Tang, "Study on damages constitutive model of rocks based on Weibull distributing," Journal of Hunan University of Science \& Technology (Natural Science Edition), vol. 22, no. 4, pp. 65-68, 2007.

[19] N. A. Al-Shayea, K. Khan, and S. N. Abduljauwad, "Effects of confining pressure and temperature on mixed-mode (I-II) fracture toughness of a limestone rock," International Journal of Rock Mechanics and Mining Sciences, vol. 37, no. 4, pp. 629-643, 2000.

[20] R. D. Dwivedi, R. K. Goel, V. V. R. Prasad, and A. Sinha, "Thermo-mechanical properties of Indian and other granites," International Journal of Rock Mechanics and Mining Sciences, vol. 45, no. 3, pp. 303-315, 2008.

[21] S. Akdag, M. Karakus, A. Taheri, G. Nguyen, and H. Manchao, "Effects of thermal damage on strain burst mechanism for brittle rocks under true-triaxial loading conditions," Rock Mechanics and Rock Engineering, vol. 51, no. 6, pp. 1657-1682, 2018.

[22] Q. S. Liu and X. C. Xu, "Damage analysis of brittle rock at high temperature," China Journal of Rock Mechanics and Engineering, vol. 19, no. 4, pp. 408-411, 2000.

[23] S. Liu and J. Xu, "An experimental study on the physicomechanical properties of two post-high-temperature rocks," Engineering Geology, vol. 185, pp. 63-70, 2015.
[24] S. Liu and J. Xu, "Analysis on damage mechanical characteristics of marble exposed to high temperature," International Journal of Damage Mechanics, vol. 24, no. 8, pp. 1180-1193, 2015.

[25] H. Tian, T. Kempka, N.-X. Xu, and M. Ziegler, "Physical properties of sandstones after high temperature treatment," Rock Mechanics and Rock Engineering, vol. 45, no. 6, pp. 1113-1117, 2012.

[26] R. Tiskatine, A. Eddemani, L. Gourdo et al., "Experimental evaluation of thermo-mechanical performances of candidate rocks for use in high temperature thermal storage," Applied Energy, vol. 171, pp. 243-255, 2016.

[27] P. K. Gautam, A. K. Verma, S. Maheshwar, and T. N. Singh, "Thermomechanical analysis of different types of sandstone at elevated temperature," Rock Mechanics and Rock Engineering, vol. 49, no. 5, pp. 1985-1993, 2016.

[28] T. Yin, X. Li, W. Cao, and K. Xia, "Effects of thermal treatment on tensile strength of Laurentian granite using Brazilian test," Rock Mechanics and Rock Engineering, vol. 48, no. 6, pp. 2213-2223, 2015.

[29] W. Zhang, Q. Sun, S. Hao, J. Geng, and C. Lv, "Experimental study on the variation of physical and mechanical properties of rock after high temperature treatment," Applied Thermal Engineering, vol. 98, pp. 1297-1304, 2016.

[30] X. Xu, F. Gao, and Z. Zhang, "Thermo-mechanical coupling damage constitutive model of rock based on the Hoek-Brown strength criterion," International Journal of Damage Mechanics, vol. 27, no. 8, pp. 1213-1230, 2017.

[31] P. K. Gautam, M. K. Jha, A. K. Verma, and T. N. Singh, "Experimental study of thermal damage under compression and tension of Makrana marble," Journal of Thermal Analysis and Calorimetry, pp. 1-19, 2019. 


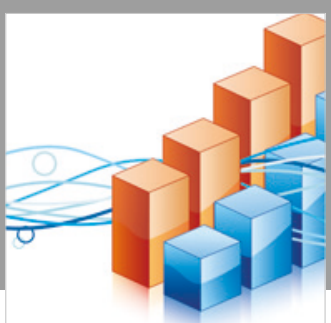

Advances in

Operations Research

\section{-n-m}
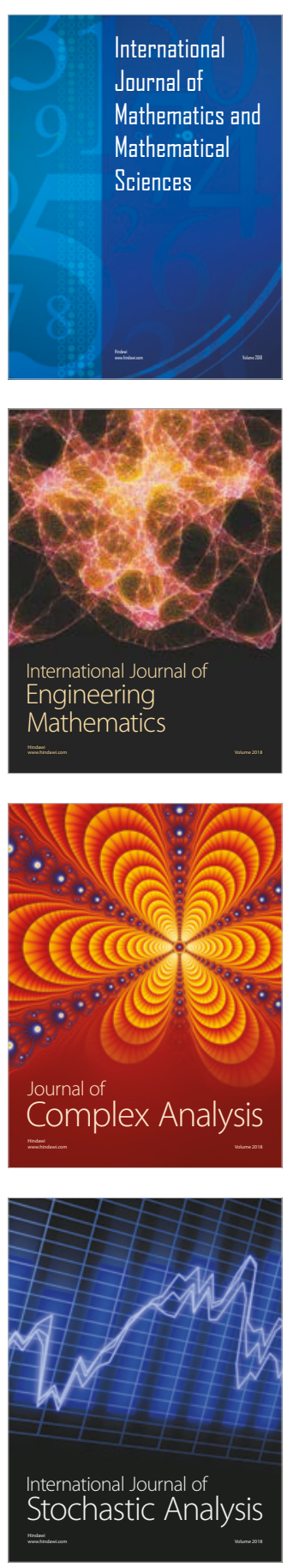
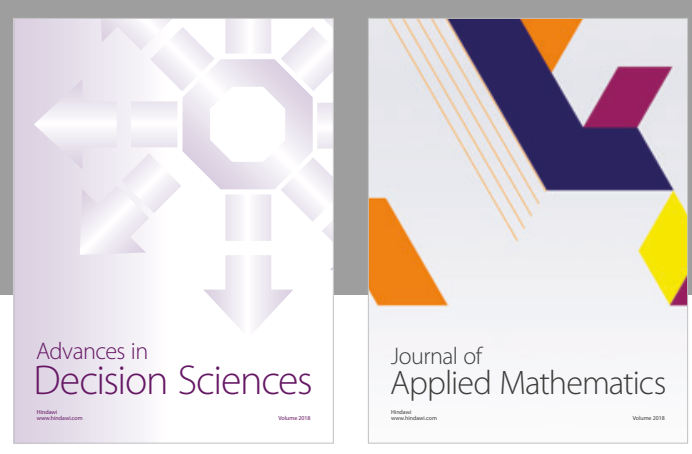

Journal of

Applied Mathematics
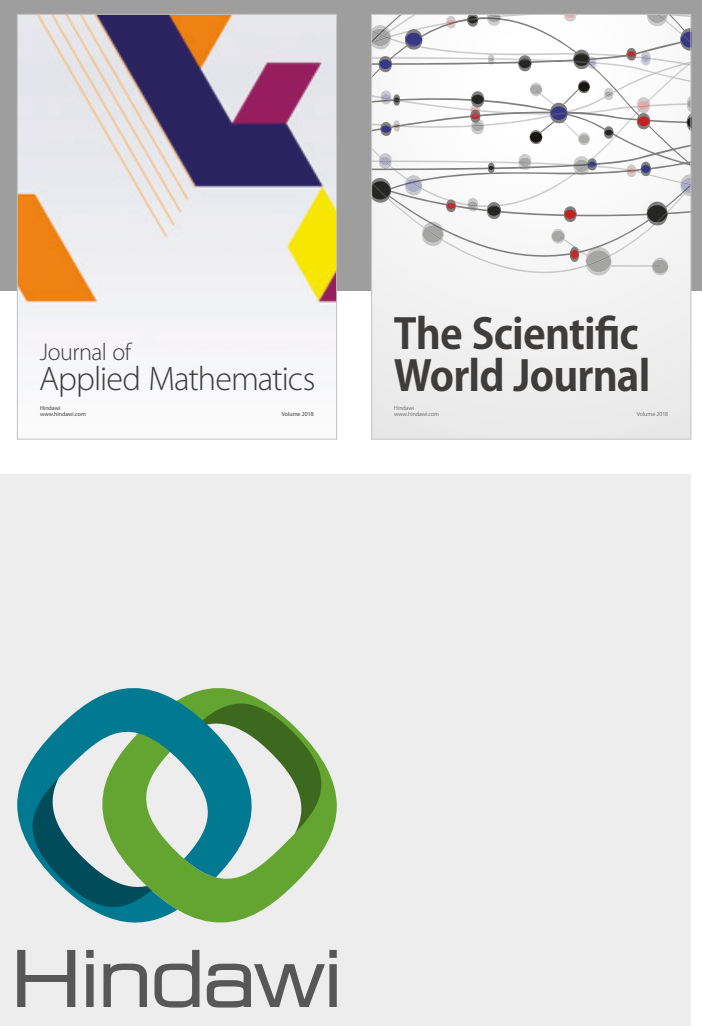

Submit your manuscripts at

www.hindawi.com

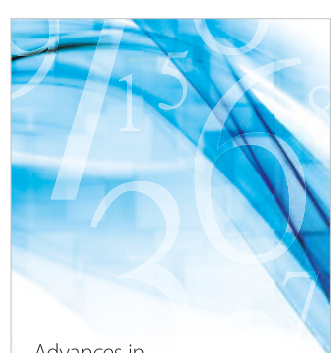

Advances in
Numerical Analysis
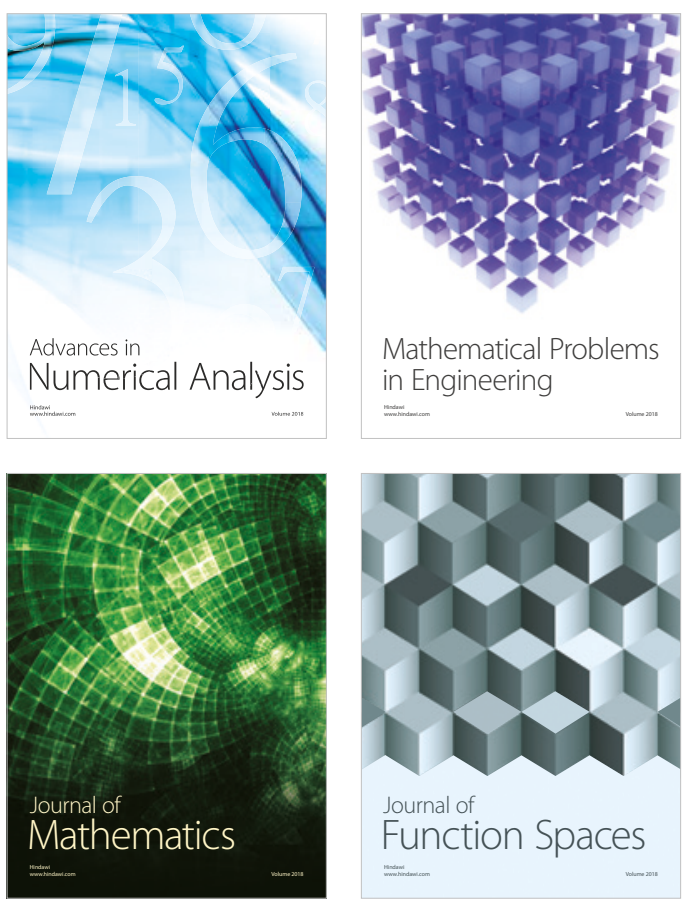

Mathematical Problems in Engineering

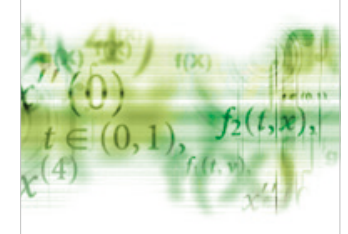

International Journal of

Differential Equations

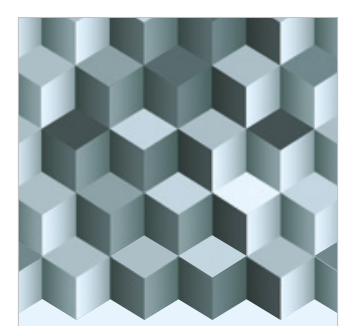

Journal of

Function Spaces

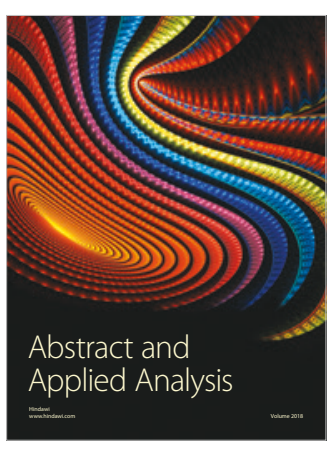

The Scientific

World Journal

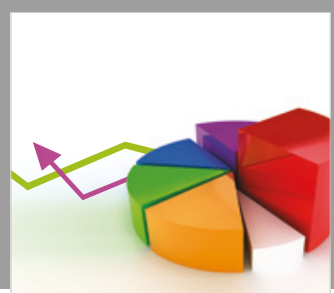

Journal of

Probability and Statistics
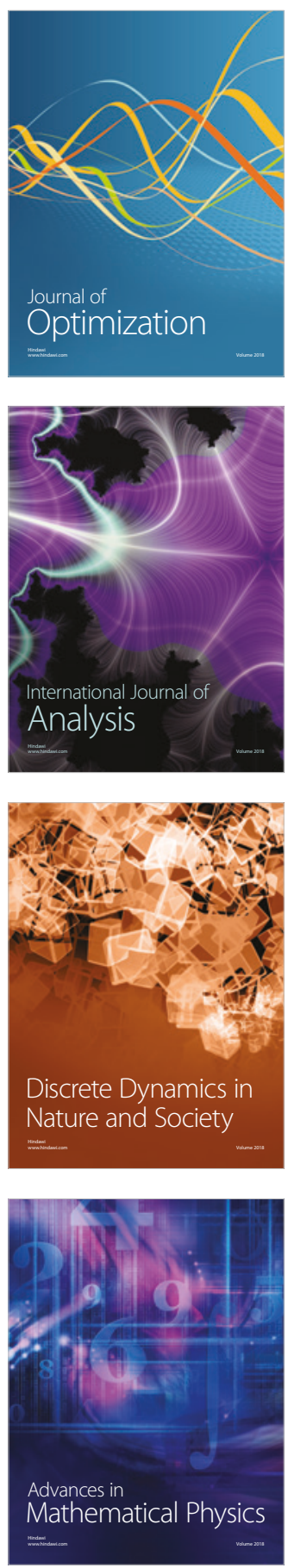